Jurnal Riset Agama

Volume 1, Nomor 3 (Desember 2021): 212-222

DOI: $10.15575 /$ jra.v1i3.15224

https://journal.uinsgd.ac.id/index.php/jra

\title{
Pemikiran Islam Wasathiyah Azyumardi Azra sebagai Jalan Moderasi Beragama
}

\author{
${ }^{1}$ Andika Putra, ${ }^{2}$ Atun Homsatun, ${ }^{3}$ Jamhari, ${ }^{4}$ Mefta Setiani, ${ }^{5}$ Nurhidayah \\ 1,3Jurusan Aqidah dan Filsafat Islam, Fakultas Ushuluddin dan Pemikiran \\ Islam, UIN Raden Fatah Palembang, Indonesia \\ 2Jurusan Komunikasi dan Penyiaran Islam, Fakultas Ushuluddin Adab \\ dan Dakwah, Institut Agama Islam Negeri Kendari, Indonesia \\ 4Jurusan Psikologi Islam, Fakultas Ushuluddin, \\ UIN Raden Intan Lampung, Indonesia \\ 5Jurusan Aqidah dan Filsafat Islam, Fakultas Ushuluddin Adab dan \\ Humaniora, Institut Agama Islam Negeri Salatiga, Indonesia \\ putraandika3812@gmail.com, homsatoen@gmail.com, \\ jamharimustafa@gmail.com, meftastn17@gmail.com, \\ kakanurulputri@gmail.com
}

\begin{abstract}
This study aims to discuss how the concept of Islam wasathiyah Azyumardi Azra as a way of religious moderation in Indonesia. This study uses a qualitative approach with descriptiveanalytical method. Regarding the data, this research is library research, so the data used are books that are directly related to this research. The results and discussion in this study seek to explore the concept of Islam wasathiyah Azyumardi Azra as a way of religious moderation in Indonesia. This study concludes that the Islamic thought of Wasathiyah Azyumardi Azra as a way of religious moderation is to actualize the values of moderation that already exist in the Qur'an, achieve peace and contribute to civilized and progressive civilization. This study recommends the Indonesian Ministry of Religion to apply wasathiyah values in Islam as a way of religious moderation.
\end{abstract}

Keywords: Azyumardi Azra; Moderation; Wasathiyah.

\begin{abstract}
Abstrak
Penelitian ini bertujuan membahas bagaimana konsep Islam wasathiyah Azyumardi Azra sebagai jalan moderasi beragama di Indonesia. Penelitian ini menggunakan pendekatan kualitatif dengan metode deskriptif-analisis. Mengenai data, penelitian ini merupakan library research, sehingga data yang digunakan adalah buku-buku yang terkait langsung dengan penelitian ini. Hasil dan pembahasan dalam penelitian ini berupaya
\end{abstract}


Jurnal Riset Agama, Volume 1, Nomor 3 (Desember 2021): 212-222

Andika Putra, Atun Homsatun, Jamhari, Mefta Setiani, Nurhidayah/Pemikiran Islam Wasathiyah Azyumardi Azra sebagai Jalan Moderasi Beragama

menyelami konsep Islam wasathiyah Azyumardi Azra sebagai jalan moderasi beragama di Indonesia. Penelitian ini menyimpulkan bahwa pemikiran Islam wasathiyah Azyumardi Azra sebagai jalan moderasi beragama adalah mengaktualisasikan nilai-nilai moderasi yang telah ada dalam al-Qur'an, mencapai kedamaian dan memberi sumbangsih terhadap peradaban berkeadaban serta berkemajuan. Penelitian ini merekomendasikan kepada Kementrian Agama Republik Indonesia untuk menerapkan nilai-nilai wasathiyah dalam Islam sebagai jalan moderasi beragama.

Kata Kunci: Azyumardi Azra; Moderasi; Wasathiyah.

\section{Pendahuluan}

Istilah wasathiyah berasal dari bahasa Arab, yaitu kata wasathan/wasathiyah yang terambil dari kata wasatha, wustha dan memiliki makna tengah dan kemudian berubah jadi istilah wasith-alwasith yang maknanya penengah (Usman, n.d, 2020: 1). Dalam al-Qur'an, istilah wasathan disebutkan dalam surah al-Baqarah [2] ayat 143:

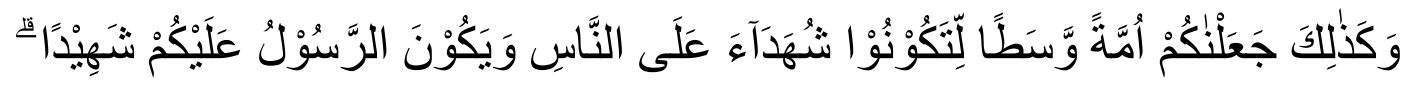

Artinya: "Dan demikian (pula) Kami telah menjadikan kamu (umat Islam), umat yang pertengahan agar kamu menjadi saksi atas (perbuatan) manusia dan agar Rasul (Muhammad) menjadi saksi atas (perbuatan) kamu."

Dalam aktualisasinya, perilaku beragama ternyata tidak senantiasa selaras dengan maksud dan tujuan dari agama itu sendiri. Banyak kekerasan dan pertikaian yang mengatasnamakan agama, termasuk Islam. Dengan hal ini, maka stigma yang muncul seolah-olah agama Islam-lah yang menjadi dalang dari perpecahan yang ada (Niam, 2019: 92). Padahal peristiwa kekerasan yang mengatasnamakan agama itu tidaklah selaras dengan sumber hukum utama umat Islam (al-Qur'an). Allah SWT. Berfirman dalam surat al-Anbiya [21] ayat 107:

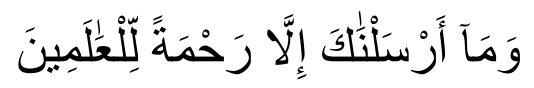

Artinya: "Dan tidaklah kami mengutusmu, melainkan untuk (menjadi) rahmat bagi semesta alam" 
Jurnal Riset Agama, Volume 1, Nomor 3 (Desember 2021): 212-222

Andika Putra, Atun Homsatun, Jamhari, Mefta Setiani, Nurhidayah/Pemikiran Islam Wasathiyah Azyumardi Azra sebagai Jalan Moderasi Beragama

Dari sinilah kemudian muncul keinginan umat Islam yang mendambakan bentuk Islam damai dan mulai menyadari bahwa perpecahan, pertikaian serta peperangan merupakan aksi yang berasal dari radikalisme dan tentu saja tidak diperbolehkan dalam syari'at (Niam, 2019: 92).

Prof. Dr. Azyumardi Azra, MA., CBE merupakan salah satu cendikiawan Islam Indonesia yang gencar dalam menyebarkan wacana Islam wasathiyah. Ia adalah cendikiawan berdarah Minang yang lahir di Lubuk Alung pada tanggal 04 Maret 1955. Riwayat pendidikannya meliputi Fakultas Tarbiyah IAIN Jakarta (1982), Master of Arts (MA) di Departemen Bahasa dan Budaya Timur Tengah Columbia University (1998), Master of Philosophy (M. Phil) dari Departemen Sejarah Columbia University (1990) dan Doctor of Philosophy Degree (1992) (Ahmad, 2013: 353).

Azyumardi Azra pernah aktif sebagai penulis di majalah Panji Masyarakat (1979-1985), dosen di Fakultas Tarbiyah IAIN Syarif Hidayatullah Jakarta (1992-sekarang), Professor Sejarah, Wakil Rektor I dan kemudian pernah menjabat sebagai Rektor UIN Syarif Hidayatullah Jakarta sampai tahun 2006. Dengan karier dan karya yang begitu memukau, akhirnya Azra pun dikenal sebagai seorang cendikiawan Islam yang pemikiran-pemikirannya banyak dikaji dan diteliti oleh berbagai kalangan.

Dalam menjabarkan tentang moderasi beragama, Azyumardi Azra kerap kali menggunakan istilah Islam Wasathiyah. Menurutnya, tradisi Islam wasathiyah di Indonesia terbentuk melalui proses sejarah yang panjang. Dimulai dengan proses Islamisasi tanpa perang yang dilakukan para ulama dengan corak inklusif, akomodatif dan akulturatif terhadap budaya lokal. Akan tetapi, hal ini pada awalnya memicu gejala sinkretisme dengan kepercayaan dan pengamalan agama lokal. Hingga kemudian gelombang pembaharuan Islam terus berlangsung dan membawa pemikiran yang tujuan akhirnya adalah menggiring umat Islam Indonesia agar lebih menyesuaikan dan dekat kepada ortodoksi Islam, baik praktik maupun pemikiran (Azra, 2017: 5).

Dengan demikian, menjadi sangat menarik untuk menelaah pemikiran Azyumardi Azra yang memiliki nuansa khas, berbeda dari pemikir-pemikir lain. Maka dari itu, penelitian ini akan mengupas bagaimana konsep Islam wasathiyah versi Azyumardi Azra dalam mendorong arus moderasi beragama di Indonesia.

Permasalahan utama penelitian ini adalah mengenai pemikiran islam wasathiyah Azyumardi Azra sebagai jalan moderasi beragama di Indonesia. Rumusan masalah dalam penelitian ini adalah bagaimana pemikiran Islam wasathiyah Azyumardi Azra sebagai jalan moderasi beragama di Indonesia. Hasil penelitian ini diharapkan memberikan implikasi manfaat, baik secara teoritis maupun praktis. Secara teoritis, 
Jurnal Riset Agama, Volume 1, Nomor 3 (Desember 2021): 212-222

Andika Putra, Atun Homsatun, Jamhari, Mefta Setiani, Nurhidayah/Pemikiran Islam Wasathiyah Azyumardi Azra sebagai Jalan Moderasi Beragama

penelitian ini diharapkan dapat memberikan sumbangan untuk memperkaya khazanah keilmuan Islam berkaitan dengan pandangan Islam wasathiyah Azyumardi Azra sebagai jalan moderasi beragama. Adapun secara praktis, penelitian ini diharapkan menjadi rujukan dalam penerapan moderasi beragama di Indonesia.

Sebagai alur logis berjalannya penelitian ini perlu dirancang kerangka berpikir. Tantangan ideologi Islam wasathiyah di kawasan Asia Tenggara (termasuk Indonesia) mengambil bentuk yang khas pada masing-masing negara (Dimyati, 2017: 140). Wacana Islam wasathiyah dihasilkan dari perkembangan sosiologis dunia Muslim, khususnya Muslim Indonesia (Najib et al., 2020: 122). Islam wasathiyah bertumpu kepada Tauhid yang tidak sekedar dalam dimensi transendental, melainkan juga dalam kehidupan sehingga tercipta tatanan sosial yang baik (Syamsuddin, 2016: 6). Wasathiyah juga termasuk karakter Islam yang utama karena nilai inilah yang senantiasa menghubungkan umat Islam dengan prinsip dasar mereka (Fitri, 2015: 52).

Penelitian terdahulu telah dilakukan oleh kalangan ahli. Di antaranya Dimyati, A. (2017), "Islam Wasatiyah; Identitas Islam Moderat Asia Tenggara dan Tantangan Ideologi," Islamic Review: Jurnal Riset dan Kajian Keislaman. Penelitian ini membahas mengenai Islam Wasatiyah yang mengajak setiap individu untuk memiliki tanggungjawab terhadap individu lain dengan solidaritas yang terbangun secara organik. Metode penelitian yang digunakan studi pustaka, yakni mengeksplor berbagai sumber penelitian yang relevan dengan Islam Wasatiyah. Hasil penelitian menunjukkan bahwa Islam Wasatiyah yang telah disepakati sebagai identitas Islam Asia Tenggara pada Halaqah Ulama Asean 2017 menjadi titik pijak bagi negara di kawasan tersebut untuk menata kembali cara pandang dan hubungan pemerintah dengan sudut pandang yang lebih netral (Dimyati, 2017: 139-168).

Najib, M. A., \& Fata, A. K. (2020), "Islam Wasatiyah dan Kontestasi Wacana Moderatisme Islam di Indonesia," Academia: Jurnal Theologia. Artikel ini menginformasikan tiga hal. Pertama, latar belakang historis wacana Islam Wasatiyah menyeruak di Indonesia. Kedua, Islam wasatiyah yang dikonsepsikan oleh organisasi keagamaan dan cendikiawan Muslim Indonesia. Dua subjek penting yang memperkenalkan Islam Wasatiyah di Indonesia adalah Majelis Ulama Indonesia (MUI) dan Azyumardi Azra. Ketiga, dalam waktu yang hampir bersamaan, wacana Islam Wasatiyah memperebutkan moderatisme Islam dengan wacana Islam Indonesia lain, seperti Islam Nusantaranya Nahdatul Ulama dan Islam Berkemajuannya Muhammadiyah. Penelitian ini menggunakan metode sejarah pemikiran, yaitu mengumpulkan sumber-sumber sejarah secara efektif dan menilainya secara kritis. Hasil pembahasan penelitian ini menunjukkan 
Jurnal Riset Agama, Volume 1, Nomor 3 (Desember 2021): 212-222

Andika Putra, Atun Homsatun, Jamhari, Mefta Setiani, Nurhidayah/Pemikiran

Islam Wasathiyah Azyumardi Azra sebagai Jalan Moderasi Beragama

bahwa wacana Islam Wasatiyah di Indonesia berkorelasi dengan gagasan Islam Wasatiyah intelektual Malaysia, Mohammad Hashim Kamali (Najib et al., 2020: 115-138).

Irawan, M. D. (2017), “Islam Wasatiyyah: Refleksi Antara Islam Modern dan Upaya Moderasi Islam," Tajdid: Jurnal Ilmu Ushuluddin. Penelitian ini membahas mengenai peran Indonesia dalam menggeser citra Islam dari sentimen kekerasan menjadi cara pandang cinta damai namun tetap dalam bingkai keislaman. Metode yang digunakan dalam penelitian ini adalah studi pustaka, yakni mengeksplor berbagai sumber penelitian yang relevan dengan masalah moderasi Islam dan Islam Wasatiyah. Hasil penelitian menunjukkan bahwa bagi negara-negara di Asia Tenggara, Indonesia-Malaysia telah memprioritaskan Islam Wasyatiyyah sebagai acuan ditengah masalah terorisme yang ada saat ini. Selain itu, konsep wasatiyyah juga memberikan opsi kepada sebuah negara untuk "memfasilitasi" dan menjembatani hubungan agama dan negara (Irawan, 2017: 111-128).

Penelitian terdahulu telah menyinggung masalah wacana Islam Wasatiyah sebagai jembatan antara negara dan agama (Dimyati, 2017: 162). Juga telah mengemukakan secara historis kemunculan wacana Islam Wasatiyah di Indonesia(Irawan, 2017: 126; Najib et al., 2020: 131). Perbedaan penelitian ini dengan beberapa penelitian terdahulu terdapat pada upaya penerapan partisipasi masyarakat (Rahmat et al., 2020: 62) sebagai metodologi bagi penerapan Islam Wasatiyah di Indonesia.

Sebagai landasan teoritis penelitian ini, maka diperlukan adanya tinjauan pustaka. Umat Islam terkotak menjadi dua golongan yang memiliki pemahaman yang cenderung bersebrangan (Junaedi, 2019: 394). Meskipun secara geografis Indonesia terletak jauh dari tempat turunnya Islam (Arab), tetapi impor wacana keagamaaan baik yang ekstrim maupun moderat tetap berlangsung (Najib et al., 2020: 134). Wacana Islam wasathiyah merupakan respon intelektual terhadap kecenderungan meningkatnya ekstrimisme (Azra, 2017: 5). Islam wasathiyah merupakan optik dari umat Islam yang memiliki cara pandang tengah, adil, hidup harmoni di tengah masyarakat yang beragam serta dinamis (Dimyati, 2017: 162). Wasathiyah juga dapat berarti konsep yang berasal dari epistimologi Islam dan bermakna penengah diantara dua hal yang saling berhadapan (Irawan, 2017: 125).

\section{Metodologi Penelitian}

Metodologi penelitian merupakan penjabaran tentang konsep teoretik berbagai metode, menyangkut kelebihan dan kekurangan yang kemudian dilanjutkan dengan menentukan metode yang digunakan (Sedarmayanti, 2002: 25). Adapun dalam penelitian ini, pendekatan yang digunakan adalah 
Jurnal Riset Agama, Volume 1, Nomor 3 (Desember 2021): 212-222

Andika Putra, Atun Homsatun, Jamhari, Mefta Setiani, Nurhidayah/Pemikiran

Islam Wasathiyah Azyumardi Azra sebagai Jalan Moderasi Beragama

kualitatif dengan metode deskriptif-analisis yang bertujuan membuat pencandraan secara sistematis, faktual dan akurat. Metode deskriptif bermakna pencarian fakta dengan interpretasi yang tepat (Samsu, 2017: 117).Mengenai data, penelitian ini merupakan library research, sehingga data yang digunakan adalah buku-buku yang terkait langsung dengan penelitian ini. Semua buku tersebut ditempatkan sesuai dengan korelasinya terhadap topik utama yang dibahas dalam penelitian ini (Hasan, 2002: 24).

\section{Hasil dan Pembahasan}

\section{Biografi Azyumardi Azra}

Prof. Dr. Azyumardi Azra, MA., CBE (selanjutnya disebut Azra) adalah seorang cendikiawan berdarah Minang. Ia lahir di Lubuk Alung, Sumatera Barat pada hari Jum'at tanggal 4 Maret 1955 M / 9 Rajab 1374 H. Ayahnya bernama Bagindo Azikar, seorang tukang kayu, pedagang cengkeh dan kopra yang berasal dari dusun Duku Sungai Limau, tak jauh dari Pariaman. Walaupun demikian, Bagindo tetap memiliki motivasi yang kuat agar anak-anaknya dapat mengenyam pendidikan yang layak dan masa depan yang cerah. Ibu Azra bernama Ramlah, seorang guru Agama lulusan Madrasah al-Manar. Azra kecil mendapat pendidikan agama langsung dari ibunya, tidak seperti kebanyakan anak Minang yang mendapat pembelajaran agama di Surau atau langgar.

Azra memulai jenjang pendidikan di SDN 01 Lubuk Alung yang terletak tidak jauh dari rumahnya. Pendidikan dasar ia selesaikan pada tahun 1963. Kemudian Azra melanjutkan ke Pendidikan Guru Agama Negeri (PGAN) Padang serta menyelesaikannya pada tahun 1975. Selanjutnya ia masuk ke Fakultas Tarbiyah IAIN Jakarta pada tahun 1982. Karena prestasinya, Azra kemudian mendapat beasiswa Fullbright meneruskan jenjang pendidikan di Departemen Bahasa dan Budaya Timur Tengah, Columbia University dan mendapat gelar Master of Arts (MA). Di tempat yang sama Azra juga mendapat gelar Master of Philosophy (M. Phil) dan meneruskan studi doktoral dengan disertasi berjudul "The Transmission of Islamic Reformism to Indonesia: Network of Middle Eastern and Malay-Indonesian 'Ulama in the Seventeenth and Eighteeth Centuries" (Handrianto, 2007: 96-99).

Dalam perjalanannya, Azra menyandang berbagai jabatan di dunia akademik. Ia pernah menjabat sebagai Pembantu Rektor I IAIN Syarif Hidayatullah Jakarta, Direktur Sekolah Pascasarjana UIN Syarif Hidayatullah Jakarta, Guru besar Sejarah Fakultas Adab IAIN Jakarta dan pernah juga diangkat sebagai Rektor UIN Syarif Hidayatullah Jakarta. Azra juga adalah orang Asia Tenggara pertama yang dinobatkan menjadi Professor Fellow dari Universitas Melbourne, Australia (Ahmad, 2013: 353). 
Jurnal Riset Agama, Volume 1, Nomor 3 (Desember 2021): 212-222

Andika Putra, Atun Homsatun, Jamhari, Mefta Setiani, Nurhidayah/Pemikiran Islam Wasathiyah Azyumardi Azra sebagai Jalan Moderasi Beragama

Ini merupakan capaian luar biasa dan membuat namanya semakin melambung di tingkat mancanegara.

Azra juga dikenal sebagai tokoh yang aktif menulis. Karya tulisnya terbilang banyak dan seringkali menjadi bahan penelitian berbagai kalangan. Karya-karyanya adalah buku berjudul "Mengenal Ajaran Kaum Sufi" yang terbit pada tahun 1984, buku "Agama di Tengah Sekularisasi Politik" terbit tahun 1985, buku "Jaringan Ulama Timur Tengah dan Kepulauan Nusantara Abad XVII dan XVIII" yang merupakan pembukuan dari disertasi doktoralnya dan terbit di tahun 1994, buku "Konteks Berteologi di Indonesia; Pengalaman Islam" yang terbit pada tahun 1999, buku berjudul "Islam Substantif" terbit pada tahun 2000 dan masih banyak lagi karya tulis lainnya (Ahmad, 2013: 355-356).

\section{Konsep Islam Wasathiyah}

Secara umum, konsep Islam wasathiyah berasal dari bahasa Arab, yaitu kata wasathan/wasathiyah yang terambil dari istilah wasatha, wustha yang memiliki makna tengah dan kemudian menjadi istilah wasith-alwasith artinya penengah (Usman, n.d, 2020: 1). Dalam al-Qur'an, istilah wasathan disebutkan di dalam surat al-Baqarah [2] ayat 143:

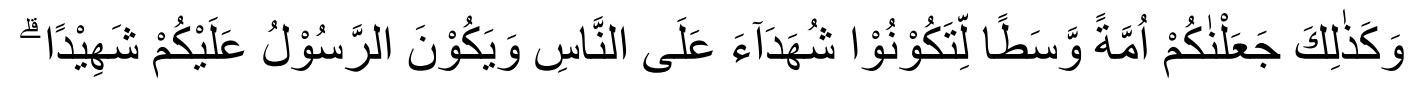

Artinya: "Dan demikian (pula) Kami telah menjadikan kamu (umat Islam), umat pertengahan agar kamu menjadi saksi atas (perbuatan) manusia dan agar Rasul (Muhammad) menjadi saksi atas (perbuatan) kamu."

Al-Asfahaniy mengartikan wasathiyah dengan makna "sawa'un", yaitu sikap tengah-tengah diantara dua paham yang saling berlawanan, sikap biasa-biasa saja atau tidak fanatik dan merasa benar sendiri, menghindarkan diri dari perilaku berlebihan dalam menjalankan agama (Irafath) dan memudah-mudahkan perkara agama (Tafrith). Sedangkan Ibnu 'Asyur menjelaskan bahwa kata "wasath' mengandung dua makna. Pertama, wasath berarti sesuatu yang memiliki dua buah ujung yang sebanding atau dapat juga berarti sesuatu yang berada di tengah. Makna pertama ini lebih dekat kepada arti secara bahasa. Adapun yang kedua, kata "wasath" mengandung makna nilai-nilai Islam yang berakar dari pola pikir lurus dan pertengahan, atau juga tidak menghendaki perilaku berlebihlebihan dalam melakukan sesuatu. Selaras dengan itu, at-Thabari juga menjelaskan bahwa "wasath" berarti terpilih, komprehensif dan adil karena terkoneksi dengan berbagai aspek dalam kehidupan manusia (Diyani, 2019: 313). 
Jurnal Riset Agama, Volume 1, Nomor 3 (Desember 2021): 212-222

Andika Putra, Atun Homsatun, Jamhari, Mefta Setiani, Nurhidayah/Pemikiran Islam Wasathiyah Azyumardi Azra sebagai Jalan Moderasi Beragama

Selain sikap tengah-tengah, wasathiyah juga berarti metode berpikir yang memiliki pengaruh etik terhadap kerangka perbuatan yang muncul dari seseorang (Dimyati, 2017: 141). Dari sini dapat kita lihat bahwa wasathiyah tidak hanya berkutat pada internal manusia saja, akan tetapi pada titik tertentu bisa mengubah tindakan yang tentu mengarah kepada keinginan untuk mencapai kedamaian (peace). Menurut Yusuf al-Qardhawi, Islam wasathiyah sendiri memiliki makna sifat keseimbangan dan moderasi yang membuat umat Islam menjadi tersatukan serta contoh bagi umat-umat lain. Sifat ini mencakup aspek keimanan dan pemikiran, simbol dan ritual, perilaku dan moral, sistem dan peraturan perundang-undangan, perasaan dan pemikiran, fisik dan metafisik, realita dan idealita serta pribadi dan kolektif (Rohmadi, 2013: 3).

Dari uraian di atas dapat disimpulkan bahwa Islam wasathiyah adalah sebuah konsep beragama yang tidak berada dalam eksklusifisme dan ekstrimisme, akan tetapi di antara keduanya (tengah-tengah). Konsep Islam wasathiyah membuat seorang Muslim menjadi pribadi yang moderat dan menjunjung perdamaian dengan tidak melunturkan jati dirinya sebagai seorang Muslim.

\section{Pemikiran Islam Wasathiyah Azyumardi Azra sebagai Jalan Moderasi Beragama}

Dalam menjabarkan tentang moderasi beragama, Azyumardi Azra kerap kali menggunakan istilah Islam Wasathiyah. Menurutnya, tradisi Islam wasathiyah di Indonesia terbentuk melalui proses sejarah yang panjang. Dimulai dengan proses Islamisasi tanpa perang yang dilakukan para ulama dengan corak inklusif, akomodatif dan akulturatif terhadap budaya lokal. Akan tetapi, hal ini pada awalnya memicu gejala sinkretisme dengan kepercayaan dan pengamalan agama lokal. Hingga kemudian gelombang pembaharuan Islam terus berlangsung dan membawa pemikiran yang tujuan akhirnya adalah menggiring umat Islam Indonesia agar lebih menyesuaikan dan dekat kepada ortodoksi Islam, baik praktik maupun pemikiran (Azra, 2017: 5).

Menurut Azra, Islam wasathiyah adalah bahasa al-Qur'an yang mengarah kepada moderasi dan merupakan jati diri Islam Indonesia (Kholis et al., 2020: 1). Moderasi Islam Indonesia tampak dalam sikap umat Islamnya yang tawasuth (sikap pertengahan), tawazun (seimbang), ta'adul (sesuai) serta tasamuh (toleran). Lawan dari wasathiyah adalah tatharruf (ekstrimisme) yang dipandang sebagai perilaku melebihi batas ketentuan syari'at, menyimpang dari nilai-nilai moderasi, menyelisihi pandangan mayoritas umat ( $r a^{\prime} y$ al-jama'ah), dan tindakan yang sudah berlebihan serta aneh jika dipandang dalam praktek lazim umat Islam.

Sikap wasathiyah akan menggiring kepada pola kaum muslimin yang inklusif, akomodatif serta toleran terhadap umat agama lain (Kholis et al., 
Jurnal Riset Agama, Volume 1, Nomor 3 (Desember 2021): 212-222

Andika Putra, Atun Homsatun, Jamhari, Mefta Setiani, Nurhidayah/Pemikiran Islam Wasathiyah Azyumardi Azra sebagai Jalan Moderasi Beragama

2020: 3). Hal ini sangat penting mengingat Indonesia adalah negara yang majemuk, plural serta kaya akan perbedaan. Tanpa sikap wasathiyah, Indonesia tentu akan ramai dengan perpecahan serta pertikaian yang pada akhirnya bisa saja menghancurkan tatanan kehidupan. Tidak kalah penting pula, moderasi beragama dengan jalan Islam wasathiyah akan mendorong umat Islam untuk mencintai kedamaian, mencegah takfirisme (paham yang mudah mengkafirkan orang lain) yang akhirnya akan memperindah tatanan kehidupan bangsa dan negara.

Azra juga menyinggung masalah moderasi beragama menyangkut politik. Menurutnya, dengan bersikap wasathiyah, umat Islam Indonesia akan dapat menerima empat hal yang fundamental dalam tatanan kenegaraan. Keempat hal itu adalah NKRI (Negara Kesatuan Republik Indonesia), Pancasila, UUD 1945 dan Bhinneka Tunggal Ika. Akan tetapi sebaliknya, dengan bersikap ekstrimis seorang muslim akan menolak hal itu dan menginginkan daulah Islamiyah atau khilafah (Kholis et al., 2020: 4).

Islam wasathiyah adalah cermin dari nilai rahmatan lil 'alamin yang terdapat dalam Islam. Dengannya, aktualisasi perdamaian akan tercapai tidak hanya bagi umat Islam Indonesia, akan tetapi juga dunia Muslim secara keseluruhan. Akhirnya, Azra menyebutkan bahwa hanya dengan kedamaian umat Islam akan dapat kembali berkontribusi dalam peradaban dan kemajuan dunia (Kholis et al., 2020: 4). Dapat disimpulkan bahwa pemikiran Islam wasathiyah Azyumardi Azra sebagai jalan moderasi beragama adalah mengaktualisasikan nilai-nilai moderasi yang telah ada dalam al-Qur'an, mencapai kedamaian dan memberi sumbangsih terhadap peradaban berkeadaban serta berkemajuan.

\section{Kesimpulan}

Istilah wasathiyah berasal dari bahasa Arab, yaitu kata wasathan/wasathiyah yang terambil dari kata wasatha, wustha dan memiliki makna tengah dan kemudian berubah jadi istilah wasith-alwasith yang maknanya penengah. Menurut Azra, Islam wasathiyah adalah bahasa alQur'an yang mengarah kepada moderasi dan merupakan jati diri Islam Indonesia. Sikap wasathiyah akan menggiring kepada pola kaum muslimin yang inklusif, akomodatif serta toleran terhadap umat agama lain. Menurutnya, dengan bersikap wasathiyah, umat Islam Indonesia akan dapat menerima empat hal yang fundamental dalam tatanan kenegaraan. Keempat hal itu adalah NKRI (Negara Kesatuan Republik Indonesia), Pancasila, UUD 1945 dan Bhinneka Tunggal Ika. Pemikiran Islam wasathiyah Azyumardi Azra sebagai jalan moderasi beragama adalah mengaktualisasikan nilai-nilai moderasi yang telah ada dalam al-Qur'an, mencapai kedamaian dan memberi sumbangsih terhadap peradaban berkeadaban serta berkemajuan. Hasil penelitian ini diharapkan 
Jurnal Riset Agama, Volume 1, Nomor 3 (Desember 2021): 212-222

Andika Putra, Atun Homsatun, Jamhari, Mefta Setiani, Nurhidayah/Pemikiran Islam Wasathiyah Azyumardi Azra sebagai Jalan Moderasi Beragama

memberikan implikasi manfaat, baik secara teoritis maupun praktis. Secara teoritis, penelitian ini diharapkan dapat memberikan sumbangan untuk memperkaya khazanah keilmuan Islam berkaitan dengan pandangan Islam wasathiyah Azyumardi Azra sebagai jalan moderasi beragama. Adapun secara praktis, penelitian ini diharapkan menjadi rujukan dalam penerapan moderasi beragama di Indonesia. Penelitian ini memiliki keterbatasan dalam melakukan analisis sehingga terbuka ruang bagi penelitian lebih lanjut secara kritis. Penelitian ini merekomendasikan kepada lembaga keagamaan untuk menerapkan nilai-nilai wasathiyah dalam Islam sebagai jalan moderasi beragama.

\section{Daftar Pustaka}

Ahmad, R. (2013). Mengenal Azyumardi Azra dalam Pemikiran Islam. Journal Analytica Islamica, 2(2), 352-370.

Azra, A. (2017). Islam Indonesia Inklusif vs Eksklusif: Dinamika Keberagaman Umat Muslimin. Makalah untuk Pengajian Ramadhan PP Muhammadiyah Kampus Universitas Muhammadiyah Jakarta, 6.

Dimyati, A. (2017). Islam Wasatiyah. Islamic Review: Jurnal Riset Dan Kajian Keislaman, 6(2), 139-168.

Diyani, T. (2019). Implementasi Paradigma Islam Wasathiyah; Strategi Menjaga Masa Depan Keindonesiaan. Salam: Jurnal Sosial dan Budaya Syar'i, 6(3), 303-316.

Fitri, A. Z. (2015). Pendidikan Islam Wasathiyah: Melawan Arus Pemikiran Takfiri Di Nusantara. Kuriositas: Media Komunikasi Sosial dan Keagamaan, $8(1), 45-54$.

Handrianto, B. (2007). 50 Tokoh Islam Liberal Indonesia: Pengusung Ide Sekularisme, Pluralisme, dan Liberalisme agama. Hujjah Press.

Hasan, M. I. (2002). Pokok-pokok Materi Metodologi Penelitian dan Aplikasinya. Jakarta: Ghalia Indonesia.

Irawan, M. D. (2017). Islam Wasatiyyah: Refleksi Antrara Islam Modern dan Upaya Moderasi Islam. Tajdid: Jurnal Ilmu Ushuluddin, 16(2), 111-128.

Junaedi, E. (2019). Inilah Moderasi Beragama Perspektif Kemenag. Harmoni, 18(2), 182-186.

Kholis, N., Azra, A., Hasan, N., Qodir, Z., Qibtyah, A., Sadzali, A., \& Min Fadhli Robby, H. (2020). Islam Indonesia 2020. UII Press Yogyakarta.

Najib, M. A., \& Fata, A. K. (2020). Islam Wasatiyah dan Kontestasi Wacana Moderatisme Islam di Indonesia. Jurnal Theologia, 31(1), 115-138.

Niam, Z. W. (2019). Konsep Islam Wasathiyah Sebagai Wujud Islam Rahmatan lil 'alamin: Peran NU dan Muhammadiyah dalam Mewujudkan Islam Damai di Indonesia. Palita: Journal of Social Religion Research, 4(2), 91-106.

Rahmat, A., \& Mirnawati, M. (2020). Model Participation Action Research 
Jurnal Riset Agama, Volume 1, Nomor 3 (Desember 2021): 212-222

Andika Putra, Atun Homsatun, Jamhari, Mefta Setiani, Nurhidayah/Pemikiran Islam Wasathiyah Azyumardi Azra sebagai Jalan Moderasi Beragama

Dalam Pemberdayaan Masyarakat. Aksara: Jurnal Ilmu Pendidikan Nonformal, 6 (1), 62.

Rohmadi, R. (2013). Al-Wasatiyyah Fil Islam Menurut Yusuf Al-Qaradhawi dan Refleksi Kritis Terhadap Ekstremisme. Universitas Muhammadiyah Surakarta.

Samsu, S. (2017). Metode Penelitian: (Teori dan Aplikasi Penelitian Kualitatif, Kuantitatif, Mixed Methods, serta Research \& Development). Pusaka Jambi.

Sedarmayanti, S. H. (2002). Metodologi Penelitian, Bandung: CV. Mandar Мaju.

Syamsuddin, D. (2016). Islam Washatiyah: Solusi Jalan Tengah. Mimbar Ulama.

Usman, A. M. (n.d.). Islam Rahmah dan Wasathiyah (Paradigma Keberislaman Inklusif, Toleran dan Damai). Humanika: Kajian Ilmiah Mata Kuliah Umum, 15(1), 18136. 